ORIGINAL ARTICLE

\title{
The effect of strength training with different frequency on untrained university students
}

\author{
Ali E. Cigerci ${ }^{1 \mathrm{ABCDE}}$, Harun Genc ${ }^{2 \mathrm{ABCDE}}$ \\ ${ }^{1}$ Kastamonu University, Kastamonu, Turkey \\ ${ }^{2}$ Bingol University, Bingol, Turkey
}

Authors' Contribution: A - Study design; B - Data collection; C - Statistical analysis; D - Manuscript Preparation; E - Funds Collection

\begin{abstract}
Purpose: $\quad$ The target of this paper was to examine the effects of strength training with different frequency on physical, performance and strength features on untrained university male students.

Material: $\quad 24$ subjects (age $=21.47+1.50$ ) were divided into three groups; 8 for strength training group once a week (ST1), 8 for strength training group three times a week (ST3) and 8 for control group (CG). The training groups were applied a 6-week ST that lasted approximately 80-90 minutes for each training 3 days a week for ST3 and once a week for ST1. Analysis of intergroup, intragroup and the effect of training were carried out with repeated measures ANOVA. Significance was set at 0.05 .

Results: $\quad$ There was no difference in body weight and body mass index values in training groups, while a significant increase was found in CG. In addition, there was a significant decrease in body fat percentage and a significant increase in skeleton muscle mass without any change in body weight and body mass index in ST3. No statistical difference was seen in 10-20 m sprint and agility tests in all groups. For vertical jump, balance test for right and left leg, there was a significant difference between the pre and post-test measurements of ST1 and ST3. In standing long jump measurements, significance was seen in favor of ST3. In strength parameter, while a significant difference was detected in bench press, shoulder press and push-up due to the development of training groups, a statistically significance was found in squat and biceps curl by reason of improvement in ST3.

Conclusions: As a conclusion, it can be said that 6-week strength training with different frequency applied on untrained male students has a positive effect on physical, performance and strength features.

Keywords: untrained university students, exercise frequency, strength training, performance analysis, physical features
\end{abstract}

\section{Introduction}

Strength training (ST) plays an important role for athletes in sports that require speed, power, strength [1] and offers many benefits for the physical fitness of individuals of all ages [2, 3]. In addition, this physical feature is also of great importance for performing many tasks in both sports and daily life $[4,5]$. For all individuals who will participate in ST, the exercise plan should be arranged according to the goals and needs of the person, and the development process should be well observed. It is also important to follow the variables of the exercise prescription.

Variables such as the type of program used and the measured prescription of the muscle activities, intensity, volume, exercise selection and application, rest times between sets and frequency can affect the magnitude of the increase in strength performance $[6,7]$. The frequency of training from these variables refers to the number of sessions performed during a specific time period and volume, intensity, selected exercises, fitness level and ability to recover, nutritional intake and exercise goals have an impact on the prescription of training frequency [7].

Although there are many studies in literature that show the effect of training frequency on strength development on different populations [8-11], these (c) Ali E.Cigerci, Harun Genc, 2020 doi:10.15561/20755279.2020.0401 studies are distinguished as those where weekly volume is equalized $[8,10]$ and not equalized $[9,11-13]$. A study reported that the training applied three days a week was optimal for strength gains of untrained healthy individuals without musculoskeletal disorders [14], while a different study stated that training frequency did not affect muscle strength gain when the training volume was equal [15]. Besides, it was understood in the studies conducted on untrained subjects that the increased frequency of training did not provide additional benefit to the strength parameter $[3,16,17]$. Thus, while it is understood that the training frequency is well documented in literature, to our knowledge, studies on untrained university students are seen to be very limited. In addition, we hypothesize that ST, which is performed with different frequency per week, can have an impact on both body composition and performance characteristics of university students. Therefore, the purpose of this study was to investigate the effect of ST with different frequency on some physical and biomotoric characteristics of untrained university students.

\section{Material and Methods}

Participants: After the pre-test process, 24 untrained male subjects were divided into three groups; 8 for strength training group once a week (ST1), 8 for strength training group three times a week (ST3) and 8 for control group 
(CG). In order to avoid any difference in physical and physiological terms, the groups were constituted in the form of 8 for ST1 $(\mathrm{age}=21.71 \pm 1.88$, height $=181.28 \pm 4.32$, weight $=71.82 \pm 6.19), \quad 8$ for ST3 $($ age $=22.00 \pm 1.51$, height $=173.75 \pm 7.20, \quad$ weight $=73.75 \pm 5.82)$ and 8 for CG $\quad$ age $=20.75 \pm 0.88$, height $=174.62 \pm 6.09$, weight $=72.12 \pm 12.78$ ). Besides, informed consent form was obtained from each subject to involve in the study.

Research Design. The training groups that participated in the study was applied a 6-week ST that lasted approximately 80-90 minutes for each training 3 days a week (Monday Wednesday, Friday) for ST3 and one day a week (Thursday) for ST1. During the training process, participants were asked to avoid challenging exercises and not to change their daily eating habits and activity levels.

Training Plan: Training load was determined as 40$60 \%$ of one repetition maximum (1RM) and the number of repetitions was 10 [18]. In the first two weeks, the training load was $40 \%$ of $1 \mathrm{RM}$, and then was increased to $50 \%$ at $3^{\text {th }}$ and $4^{\text {th }}$ weeks and $60 \%$ at $5^{\text {th }}$ and $6^{\text {th }}$ weeks. Besides, in the training planned as 3 sets, rest between repetitions was 1 minute and rest between sets was 2 minutes. While ST groups applied shoulder press, biceps curl, squat, bench press, sit-up, triceps push down, push-up, back extension movements in each training respectively, the control group continued their daily activities [19].

Physical Tests: In this part, the information about height, body weight (BW), body mass index (BMI), body fat percentage (BFP), skeleton muscle mass (SMM) parameters of subjects will be explained.

The height was measured by using Holtain brand stadiometer (Holtain, UK) with $1 \mathrm{~mm}$ accuracy and BW was determined with a sensitivity of $1 \mathrm{gr}$ in anatomical position. BMI of subjects was determined by "BMI $=\mathrm{BW}$ (kg) / (height) ${ }^{2 "}$ " formula. BFP and SMM were measured by bioimpedance analysis (Tanita MC 780; Tokyo, Japan).

Biomotoric Performance and Field Tests: Vertical jump (VJ), standing long jump (SLJ), star excursion balance test (SEBT), 10-20m sprint, T agility test (TAT), running-based anaerobic sprint test (RAST), dynamic strength and push-up tests were used to decide the performance parameters of subjects.

Jump Tests: VJ test - the difference between the point touched by jumping and the starting point was calculated. The participants is standing erect with the feet flat on the floor, after the height that the subject could reach was taken as the starting point. SLJ test - the distance between the back of the heel at the landing point and the starting line was measured. The participant jumped from the back of the starting line to the furthest possible point. Better of two attempts was recorded as "cm" for both tests [20].

Star Excursion Balance Test (SEBT): The participants were asked to touch the furthest point where they could reach eight directions with an angle of $45^{\circ}$. The test was performed three times for both feet. The balance score was calculated with the formula "reach distance / leg length x 100" [21].

Sprint Test: $10-20 \mathrm{~m}$ sprint tests were started from the starting line positioned one meter behind the start photocell (Newtest 2000; Newtest Oy, Oulu, Finland). Better of two trials was recorded as "seconds".

T Agility Test: TAT was created from 4 contact points in the shape of $\mathrm{T}, 10 \mathrm{~m}$ long and $10 \mathrm{~m}$ wide. In the test, the subjects ran to a cone $10 \mathrm{~m}$ from the starting point and went to the second cone $5 \mathrm{~m}$ away with a shuffle on the right. When the subjects touched the cone, they went to the cone $10 \mathrm{~m}$ away with a side shuffle and then returned to the middle cone with the side shuffle. The test was completed by pedalling back to the starting point [22]

Running-based Anaerobic Sprint Test (RAST): RAST included six $35 \mathrm{~m}$ maximal efforts with passive recovery intervals of 10 seconds. The time of each $35 \mathrm{~m}$ effort was recorded using photocells (Newtest 2000; Newtest Oy, Oulu, Finland) at the beginning and at end of the $35 \mathrm{~m}$ run. After the test, peak power (RPP), average power (RAP), minimum power (RMP) and fatigue index (FI) of subjects were calculated as mentioned before [23].

Dynamic Strength Tests: Dynamic strength tests consisted of bench press, squat, shoulder press and biceps curl. In the study, 1RM (Repetition Maximum) results of subjects were recorded for each movement in the evaluation of strength parameter. In order to obtain 1RM results, values were recorded on the estimation of 1RM rather than directly determining $1 \mathrm{RM}$.

As stated in literature, 1RM predictions reflect actual $1 \mathrm{RM}$ results $[24,25]$ and also do not harm the health of subjects and prevent injury [26]. In order to estimate $1 \mathrm{RM}$, subjects were asked to apply movements until they were tired. If the subject did not perform the movement optimally or gave up voluntarily, the last proper performance was recorded and 1RM was found according to Brzycki formula [27], which has been considered to be quite reliable [28].

Push-up Test: This test was applied to the participants for 30 seconds and only optimal applications were recorded as push-up score.

Statistical Analysis. The data obtained from the pre and post-training measurements of participants were analysed in SPSS 22 statistical program. Descriptive statistics are categorized according to all subjects and groups. The pre- and post-test distributions of the variables were examined according to groups. The normality of the distributions and the homogeneity of the variance were determined by the Shapiro Wilk test and the Mauchly's Sphericity test. Analysis of intergroup, intragroup, and the effect of training were carried out with Repeated Measures ANOVA. Bonferroni test was used for Post Hoc comparisons; the significance level was accepted as 0,05 .

\section{Results}

In Table 1, it is understood that there is no significant difference for all descriptive variables among groups before the training period $(\mathrm{p}>0.05)$.

In Table 2, no statistically significance was found in the height of the subjects. There was no difference in the BW and BMI values in training groups, while a significant increase was seen in these values in CG. In 
Table 1. Descriptive statistics of participants.

\begin{tabular}{|c|c|c|c|c|c|c|c|}
\hline Variables & $n$ & Group & Average+S.D & Min. & Max. & & \\
\hline \multirow{4}{*}{ ST1 } & 8 & Age ( year) & $21.71 \pm 1.88$ & 19 & 25 & & \\
\hline & 8 & Height (cm) & $181.28 \pm 4.32$ & 172.00 & 184.00 & & \\
\hline & 8 & BW (kg) & $71.82 \pm 6.19$ & 63.00 & 82.00 & & \\
\hline & & $\mathrm{BMI}\left(\mathrm{kg} / \mathrm{m}^{2}\right)$ & $21.66 \pm 1.60$ & 19.66 & 24.22 & & \\
\hline \multirow{4}{*}{ ST3 } & 8 & Age ( year) & $22.00 \pm 1.51$ & 19 & 24 & & \\
\hline & 8 & Height (cm) & $173.75 \pm 7.20$ & 163.00 & 183.00 & & \\
\hline & 8 & BW (kg) & $73.75 \pm 5.82$ & 62.00 & 82.00 & & \\
\hline & & $\mathrm{BMI}\left(\mathrm{kg} / \mathrm{m}^{2}\right)$ & $24.49 \pm 2.25$ & 20.48 & 27.51 & & \\
\hline \multirow{5}{*}{ CG } & 8 & Age ( year) & $20.75 \pm 0.88$ & 19 & 22 & & \\
\hline & 8 & Height (cm) & $174.62 \pm 6.09$ & 166.00 & 185.00 & & \\
\hline & 8 & BW (kg) & $72.12 \pm 12.78$ & 56.00 & 97.00 & & \\
\hline & & $\mathrm{BMI}\left(\mathrm{kg} / \mathrm{m}^{2}\right)$ & $23.68 \pm 5.25$ & 17.87 & 35.20 & & \\
\hline & & & & & & Chi-Square $\left(X^{2}\right)$ & p \\
\hline \multirow{4}{*}{ Total } & \multirow{4}{*}{24} & Age ( year) & $21.47 \pm 1.50$ & 19 & 25 & 4.352 & 0.114 \\
\hline & & Height (cm) & $176.26 \pm 6.62$ & 163.00 & 185.00 & 5.098 & 0.078 \\
\hline & & BW (kg) & $72.34 \pm 8.63$ & 56.00 & 97.00 & 1.966 & 0.374 \\
\hline & & $\mathrm{BMI}\left(\mathrm{kg} / \mathrm{m}^{2}\right)$ & $23.35 \pm 3.54$ & 17.87 & 35.20 & 5.422 & 0.066 \\
\hline
\end{tabular}

NOTE: *p > 0.05; BW: Body Weight, BMI: Body Mass Index.

Table 2. Comparison of physical features among groups

\begin{tabular}{|c|c|c|c|c|c|c|c|}
\hline Variables & $\mathbf{n}$ & Group & $\begin{array}{l}\text { Pre-Test } \\
\mathrm{X} \pm \mathrm{SS}\end{array}$ & $\begin{array}{l}\text { Post-Test } \\
\mathrm{X} \pm \mathrm{SS}\end{array}$ & $\begin{array}{l}\text { In-group } \\
\text { Change(\%) }\end{array}$ & $\begin{array}{l}\text { Test*Group } \\
\text { F }\end{array}$ & $\mathbf{p}$ \\
\hline & 8 & ST1 & $181.00 \pm 4.32$ & $181.14+4.45$ & $0.14(\% 0.07)$ & & \\
\hline \multirow[t]{3}{*}{ Height (cm) } & 8 & ST3 & $173.75 \pm 7.20$ & $173.87 \pm 7.39$ & $0.12(\% 0.06)$ & 0.006 & 0.994 \\
\hline & 8 & CG & $174.62 \pm 6.09$ & $174.75 \pm 5.99$ & $0.13(\% 0.07)$ & & \\
\hline & 8 & ST1 & $71.00 \pm 6.19$ & $71.85 \pm 5.95$ & 0.85 ( \% 1.19) & & \\
\hline \multirow[t]{3}{*}{ BW (kg) } & 8 & ST3 & $74.93 \pm 6.66$ & $75.62 \pm 6.75$ & 0.69 ( \% 0.92) & 15.639 & $0.001 *$ \\
\hline & 8 & CG & $72.12 \pm 12.78$ & $73.25 \pm 12.60$ & $1.13(\% 1.56)^{*}$ & & \\
\hline & 8 & ST1 & $21.66 \pm 1.60$ & $21.74 \pm 1.69$ & $0.08(\% 0.36)$ & & \\
\hline \multirow[t]{3}{*}{$\mathrm{BMI}\left(\mathrm{kg} / \mathrm{m}^{2}\right)$} & 8 & ST3 & $24.49 \pm 2.57$ & $24.71 \pm 2.06$ & 0.22 ( \% 0.89) & 13.574 & $0.001 *$ \\
\hline & 8 & CG & $23.68 \pm 5.25$ & $24.16 \pm 5.20$ & $0.48(\% 2.02)^{*}$ & & \\
\hline & 8 & ST1 & $10.71 \pm 6.75$ & $11.57 \pm 7.39$ & $0.86(\% 8.02)$ & & \\
\hline \multirow[t]{3}{*}{ BFP (\%) } & 8 & ST3 & $14.50 \pm 5.04$ & $13.43 \pm 4.40$ & $-1.07(\%-7.37)^{*}$ & 5.131 & $0.016 *$ \\
\hline & 8 & CG & $14.37 \pm 7.11$ & $14.62 \pm 6.96$ & 0.25 ( \% 1.73) & & \\
\hline & 8 & ST1 & $57.62 \pm 5.95$ & $58.12 \pm 5.54$ & 1.38 ( \% 2.39) & & \\
\hline \multirow[t]{2}{*}{ SMM (kg) } & 8 & ST3 & $59.62 \pm 4.59$ & $62.50 \pm 4.40$ & $2.88(\% 4.83)^{*}$ & 6.134 & $0.007 *$ \\
\hline & 8 & CG & $59.85 \pm 2.79$ & $60.28 \pm 3.14$ & 0.72 ( \% 1.20) & & \\
\hline
\end{tabular}

NOTE: *p< 0.05; BW: Body Weight, BMI: Body Mass Index, BFP: Body Fat Percentage, SMM: Skeleton Muscle Mass. 
addition, there was a significant decrease in BFP and a significant increase in SMM without any change in BW and BMI values in ST3.

When the performance parameters of groups are examined, there is no statistical difference in the $10 \mathrm{~m}$ and $20 \mathrm{~m}$ sprint and TAT in all groups (Table 3). In VJ and SEBTR measurements of the subjects. It is seen that there is test*group interaction and test*group interaction in these parameters caused by a significant increase in the results of ST1 and ST3. When the SLJ measurements of the subjects are analysed, test*group interaction is caused by a significant improvement in ST3. When the SEBTL measurements of the subjects are analysed, there is a significant difference in this parameter between the pre and post-test measurements of ST1 and ST3, however, this development does not affect the test*group interaction.

When the dynamic strength tests of groups are analysed, it is seen that there is test*group interaction in all parameters (Table 4). In BP, SP and PU measurements of the subjects, test*group interaction in these parameters is caused by a significant increase in the results of ST1 and ST3. In SQ and BC measurements, test*group interaction in these parameters is due to the development of ST3.

When the RAST measurements of the subjects are investigated, it is understood that there is no significant difference for all variables among groups except RAP

Table 3. Comparison of performance tests among groups

\begin{tabular}{|c|c|c|c|c|c|c|c|}
\hline Variables & $\mathbf{n}$ & Group & $\begin{array}{l}\text { Pre-Test } \\
\mathrm{X} \pm \text { SS }\end{array}$ & $\begin{array}{l}\text { Post-Test } \\
\mathrm{X} \pm \text { SS }\end{array}$ & $\begin{array}{l}\text { In-group } \\
\text { Change (\%) }\end{array}$ & $\begin{array}{l}\text { Test*Group } \\
\text { F }\end{array}$ & $\mathbf{p}$ \\
\hline & 8 & ST1 & $35.28+\underline{9} .19$ & $37.85 \pm 7.21$ & $2.57(\% 7.28)^{*}$ & & \\
\hline \multirow[t]{3}{*}{$\mathrm{VJ}(\mathrm{cm})$} & 8 & ST3 & $34.75 \pm 4.09$ & $39.75 \pm 5.28$ & $5.00(\% 14.38)^{*}$ & 3.594 & $0.046 *$ \\
\hline & 8 & CG & $33.62 \pm 3.96$ & $34.25+4.33$ & 0.63 (\% 1.87) & & \\
\hline & 8 & ST1 & $223.71 \pm 19.48$ & $224.14 \pm 19.48$ & $0.43(\% 0.19)$ & & \\
\hline \multirow[t]{3}{*}{$\mathrm{SLJ}(\mathrm{cm})$} & 8 & ST3 & $217.00 \pm 17.45$ & $223.12 \pm 17.55$ & $6.12(\% 2.82) *$ & 15.624 & $0.000 *$ \\
\hline & 8 & CG & $205.75 \pm 19.71$ & $206.00 \pm 19.91$ & $0.25(\% 0.12)$ & & \\
\hline & 8 & ST1 & $601.57 \pm 62.38$ & $667.85 \pm 67.39$ & $66.28(\% 11.01)^{*}$ & & \\
\hline \multirow[t]{3}{*}{ SEBTR } & 8 & ST3 & $625.50+53.22$ & $722.50+73.73$ & $97.00(\% 15.50) *$ & 6.766 & $0.006^{*}$ \\
\hline & 8 & CG & $677.12 \pm 85.86$ & $674.37 \pm 66.61$ & $2.75(\% 0.40)$ & & \\
\hline & 8 & ST1 & $616.71 \pm 33.59$ & $662.71 \pm 41.13$ & $46.00(\% 7.45)^{*}$ & & \\
\hline \multirow[t]{3}{*}{ SEBTL } & 8 & ST3 & $598.62+68.37$ & $664.62+54.81$ & $66.00(\% 11.02)^{*}$ & 1.232 & 0.313 \\
\hline & 8 & $\mathrm{CG}$ & $664.37 \pm 91.81$ & $690.12 \pm 73.46$ & 25.75 (\% 3.87) & & \\
\hline & 8 & ST1 & $2.07 \pm 0.07$ & $2.05 \pm 0.07$ & $0.02(\% 0.96)$ & & \\
\hline \multirow[t]{3}{*}{10 m sprint (sec) } & 8 & ST3 & $2.01 \pm 0.05$ & $1.97 \pm 0.02$ & 0.04 ( \% 1.99) & 0.542 & 0.590 \\
\hline & 8 & CG & $2.06 \pm 0.09$ & $2.04 \pm 0.07$ & $0.02(\% 0.97)$ & & \\
\hline & 8 & ST1 & $4.34 \pm 0.06$ & $4.31 \pm 0.07$ & $0.03(\% 0.69)$ & & \\
\hline \multirow[t]{3}{*}{20 m sprint (sec) } & 8 & ST3 & $4.41 \pm 0.04$ & $4.37 \pm 0.07$ & $0.04(\% 0.90)$ & 1.054 & 0.367 \\
\hline & 8 & CG & $4.38 \pm 0.06$ & $4.37 \pm 0.06$ & $0.01(\% 0.22)$ & & \\
\hline & 8 & ST1 & $10.48+0.66$ & $10.36 \pm 0.71$ & 0.12 ( \% 1.14) & & \\
\hline \multirow[t]{2}{*}{ TAT (sec) } & 8 & ST3 & $10.44 \pm 0.66$ & $10.30 \pm 0.70$ & 0.14 ( \% 1.34) & 0.210 & 0.812 \\
\hline & 8 & CG & $10.82 \pm 0.48$ & $10.76 \pm 0.50$ & $0.06(\% 0.55)$ & & \\
\hline
\end{tabular}

NOTE: *p < 0.05; VJ: Vertical Jump, SLJ: Standing Long Jump, SEBTR: Star Excursion Balance Test Right, SEBTL: Star Excursion Balance Test Left, TAT: T Agility Test, RAST: Running-based Anaerobic Sprint Test 
Table 4. Comparison of pre and post-test changes of dynamic strength tests among groups

\begin{tabular}{|c|c|c|c|c|c|c|c|}
\hline Variables & $\mathbf{n}$ & Group & Pre-Test $\mathrm{X} \pm \mathrm{SS}$ & Post Test X $\pm S S$ & $\begin{array}{l}\text { In-group } \\
\text { Change (\%) }\end{array}$ & $\begin{array}{l}\text { Test*Group } \\
\text { F }\end{array}$ & $\mathbf{p}$ \\
\hline \multirow{3}{*}{$\mathrm{BP}(\mathrm{kg})$} & 8 & ST1 & $54.28 \pm 12.39$ & $61.42 \pm 16.25$ & $7.14(\% 13.15)^{*}$ & \multirow{3}{*}{8.617} & \multirow{3}{*}{$0.002^{*}$} \\
\hline & 8 & ST3 & $65.00 \pm 15.11$ & $79.37 \pm 15.45$ & $14.37(\% 22.10)^{*}$ & & \\
\hline & 8 & CG & $46.87 \pm 9.61$ & $48.12 \pm 9.97$ & 1.25 (\% 2.66) & & \\
\hline \multirow{3}{*}{$\mathrm{SQ}(\mathrm{kg})$} & 8 & ST1 & $75.00 \pm 5.77$ & $81.42 \pm 11.07$ & $6.42(\% 8.56)$ & \multirow{3}{*}{3.774} & \multirow{3}{*}{$0.041 *$} \\
\hline & 8 & ST3 & $86.25 \pm 22.79$ & $105.62 \pm 24.11$ & $19.37(\% 22.45)^{*}$ & & \\
\hline & 8 & CG & $71.87 \pm 10.32$ & $77.50 \pm 12.53$ & $5.63(\% 7.83)$ & & \\
\hline \multirow{3}{*}{$\mathrm{SP}(\mathrm{kg})$} & 8 & ST1 & $42.85 \pm 9.51$ & $55.00 \pm 14.71$ & 12.15 ( \% 28.35)* & \multirow{3}{*}{6.395} & \multirow{3}{*}{$0.007^{*}$} \\
\hline & 8 & ST3 & $48.75 \pm 11.57$ & $68.62 \pm 23.08$ & $19.87(\% 40.75)^{*}$ & & \\
\hline & 8 & CG & $35.62 \pm 4.95$ & $38.43 \pm 5.49$ & $2.81(\% 7.88)$ & & \\
\hline \multirow{3}{*}{$\mathrm{BC}(\mathrm{kg})$} & 8 & ST1 & $34.28 \pm 6.07$ & $37.85 \pm 6.36$ & 3.57 ( \% 10.41) & \multirow{3}{*}{14.785} & \multirow{3}{*}{$0.000 *$} \\
\hline & 8 & $\mathrm{ST} 3$ & $36.25 \pm 6.94$ & $47.87 \pm 5.89$ & $11.62(\% 32.05)^{*}$ & & \\
\hline & 8 & CG & $31.87 \pm 3.72$ & $33.75 \pm 5.17$ & $1.88(\% 5.89)$ & & \\
\hline \multirow{3}{*}{ PU (rep) } & 8 & ST1 & $18.14 \pm 3.67$ & $24.14 \pm 3.18$ & $6.00(\% 33.07)^{*}$ & \multirow{3}{*}{27.674} & \multirow{3}{*}{$0.000 *$} \\
\hline & 8 & ST3 & $21.87 \pm 5.81$ & $29.50 \pm 6.54$ & 7.63 ( \% 34.88)* & & \\
\hline & 8 & CG & $22.87 \pm 4.42$ & $22.37 \pm 4.47$ & $-0.50(\%-2.18)$ & & \\
\hline
\end{tabular}

NOTE: * p< 0.05; BP: Bench Press, SQ: Squat, SP: Shoulder Press, BC: Biceps Curl, PU: Push-up.

Table 5. Comparison of pre and post-test changes of RAST among groups

\begin{tabular}{|c|c|c|c|c|c|c|c|}
\hline Variables & $\mathbf{n}$ & Group & Pre-Test $\mathrm{X} \pm \mathrm{SS}$ & Post Test X \pm SS & $\begin{array}{l}\text { In-group } \\
\text { Change (\%) }\end{array}$ & $\begin{array}{l}\text { Test*Group } \\
\text { F }\end{array}$ & $\mathbf{p}$ \\
\hline \multirow{3}{*}{ RPP (Watt) } & 8 & ST1 & $497.37 \pm 99.95$ & $524.00 \pm 99.05$ & 26.63 (\% 5.35) & \multirow{3}{*}{0.068} & \multirow{3}{*}{0.934} \\
\hline & 8 & ST3 & $609.00 \pm 175.75$ & $648.00 \pm 161.38$ & 39.00 ( \% 6.40) & & \\
\hline & 8 & CG & $641.00 \pm 105.59$ & $657.25 \pm 142.26$ & 16.25 ( \% 2.53) & & \\
\hline \multirow{3}{*}{ RAP (Watt) } & 8 & ST1 & $495.37 \pm 53.20$ & $527.25 \pm 63.47$ & $31.88(\% 6.43)$ & \multirow{3}{*}{2.191} & \multirow{3}{*}{0.138} \\
\hline & 8 & ST3 & $440.00 \pm 60.98$ & $511.57 \pm 66.65$ & $71.57(\% 16.26)^{*}$ & & \\
\hline & 8 & CG & $364.62+65.08$ & $383.25 \pm 72.61$ & 24.88 (\% 6.82) & & \\
\hline \multirow{3}{*}{ RMP (Watt) } & 8 & ST1 & $266.75 \pm 58.56$ & $297.00 \pm 66.59$ & 30.25 (\% 11.34) & \multirow{3}{*}{2.695} & \multirow{3}{*}{0.092} \\
\hline & 8 & ST3 & $328.57 \pm 55.44$ & $366.42 \pm 64.05$ & $37.85(\% 11.51)$ & & \\
\hline & 8 & CG & $376.25+46.11$ & $401.62 \pm 71.11$ & $25.37(\% 6.74)$ & & \\
\hline \multirow{3}{*}{$\mathrm{FI}(\%)$} & 8 & ST1 & $7.71 \pm 3.45$ & $8.00 \pm 2.70$ & $0.29(\% 3.76)$ & \multirow{3}{*}{0.018} & \multirow{3}{*}{0.982} \\
\hline & 8 & ST3 & $7.75 \pm 3.19$ & $8.12 \pm 3.64$ & 0.37 ( \% 4.77) & & \\
\hline & 8 & CG & $6.25 \pm 2.54$ & $6.50 \pm 1.92$ & $0.25(\% 4.00)$ & & \\
\hline
\end{tabular}

NOTE: * P< 0.05; RPP: RAST Peak Power, RAP: RAST Average Power, RMP: RAST Minimum Power, FI: Fatigue Index.

parameter (Table 5). This significance results from the development of the ST3 in the post-test measurements.

\section{Discussion}

The purpose of current study was to examine to the effects of ST with different frequency on physical, performance and strength features on untrained university male students.

In physical features, it was understood that although there is no statistical difference in the height of the subjects, there is a significant difference in BW and BMI of CG. When BFP and SMM measurements of the subjects are analysed, the test*group interaction is caused by a significant improvement in the results of ST3. BW, BMI, BFP change may vary depending on the type, duration, intensity and frequency of the training. BW and BMI generally increase in maximal strength studies performed to create muscle hypertrophy $[29,30]$. Crewther et al. 
investigated the effects of 6-week resistance training on strength and body composition, and at the end of the program, they detected a $1 \%$ decrease in body fat and $1.3 \%$ increase in lean body weight. According to this information, as a result of training performed 3 days a week, it was understood that BW remained constant while the body composition changed, meaning that there was an increase in muscle mass and a decrease in body fat. Thus, it is thought that the training sessions play an important role in the anabolic process due to hormonal changes and have a positive effect on the increase of muscle mass while the fat percentage decreases.

In performance parameter, it was detected that while there is no significance in sprint and agility tests, a statistically significance was found in VJ and balance tests between the pre and post-test measurements of ST1 and ST3. Significance was also seen in SLJ because of the improvement of ST3. Styles et al. applied ST on 1718 aged male elite footballers for 6 weeks. As a result of ST, they detected a statistically significant difference in squat and sprint performances. The results of this study differ from our study. As is known, speed is a genetic ability. However, it is known that speed can be improved by $10-15 \%$ with special and systematic exercises [33]. Therefore, it is considered that the speed and agility features of the subjects did not develop because of the fact that no special exercises were applied to improve speed or agility in ST program implemented in this study, they were not elite athletes and may have had low percentage of fast twitch fibril type. According to the information in literature, the explosive force is a feature that can be improved by training [34]. Dello Iacono et al. looked at the effect of force exercises on the lower limbs on footballers. They stated that strength exercises are beneficial for the development of lower limb strength and jumping force when added to training of football players [35]. Hung et al., in their study, reached the conclusion that strength exercises performed on 21 male athletes for 8 weeks improved the balance results of the participants [36]. These studies support our results. As a result of ST, it can be said that especially squat exercise in our program causes an increase in leg muscle strength and this situation positively increases VJ, SLJ and dynamic balance features.

In strength parameter, it was determined that while statistical significance in BP, SP and PU was caused by the development of training groups, the significant difference in SQ and BC was due to the improvement of ST3. According to the researches, there are many factors that affect the force; it may change depending on the strength development, the size of the muscles contracting, the duration and scope of the contraction, the quality of the training, the number, the methods applied, the working order, the working ankle of the joints, external factors such as nutrition and seasonal conditions [18]. Hermassi et al. applied ST 3 days a week for 8 weeks to 34 elite male handball players, whose ages varied between 16 and 19 . They found a statistically significant difference between 1 maximum bench press pre-test and post-test results [37]. As a result of a study the development of the group who worked out 4 times a week was higher than those who worked out 2 and 3 times after eight months of training [38]. In another study, McKenzie examined strength gains on untrained males who performed bench press lifts once, twice, three, four or five times a week for 8 weeks [39]. The result suggested that the group who worked out 5 times a week had greater strength improvements than the other groups [39]. The results of current study are similar to the results revealed in these researches applied on untrained subjects. Accordingly, it is thought that the number of strength training applied per week affects the amount of muscle hypertrophy and strength gain.

In anaerobic power measurements of the subjects, there is a significant difference in RAP between the pre and post-test measurements of ST3. Although it is known that strength training increases anaerobic power, there is no statistically significant difference in RPP, RMP, FI results. It is thought that the reason for this is that the subjects are untrained individuals, they have not actively involved in any sports branch before and they generally lead a sedentary lifestyle. When other tests giving an idea about anaerobic power are examined, it was seen that ST1 and ST3 made progress in VJ and ST3 improved in SLJ significantly. Although the RAST results do not support the jump results, it is figured out that the reason why the subjects have a significant difference in the jump results is that they are familiar with the jump style movements rather than pedalling. Besides, the increase of RAP value of ST3 shows that the strength resistance feature of subjects has improved in terms of intensity and volume.

\section{Conclusion}

According to the results in current study and the information in literature, it is seen that factors such as the type, intensity, duration and frequency of the exercise selected in the application of ST, as well as the physical fitness level of the participants are important. In particular, it is observed that body composition, performance characteristics and strength gain are more effective in untrained individuals who apply ST three times a week than the ones who participate in ST once or twice a week. In conclusion, it can be said that 6-week strength training applied on untrained male students has a positive effect on physical, performance and strength features. Also, frequency of training plays a key role.

\section{Conflict of interest}

The authors declare no conflict of interest. 


\section{References}

1. Fry AC. The role of resistance exercise intensity on muscle fibre adaptations. Sports Med, 2004;34(10):663-679. https://doi.org/10.2165/00007256-200434100-00004

2. Phillips S, Winett R. Uncomplicated resistance training and health-related outcomes: Evidence for a public health mandate. Curr Sports Med Rep, 2010;9(4):208-213. https://doi.org/10.1249/JSR.0b013e3181e7da73

3. Arazi H, Asadi A, Aziri H, Asadi A, Arazi H, Asadi A. Effects of 8 weeks equal-volume resistance training with different workout frequency on maximal strength, endurance and body composition. Int J Sports Sci Eng, 2011;5(2):112-118.

4. Steib S, Schoene D, Pfeifer K. Dose-response relationship of resistance training in older adults: a metaanalysis. Med Sci Sports Exerc, 2010;42(5):902-914. https://doi.org/10.1249/MSS.0b013e3181c34465

5. Suchomel TJ, Nimphius S, Stone MH. The importance of muscular strength in athletic performance. Sports Med, 2016;46(10):1419-1449. https://doi.org/10.1007/s40279-016-0486-0

6. American College of Sports Medicine. American College of Sports Medicine position stand. Progression models in resistance training for healthy adults. Med Sci Sports Exerc, 2009;41(3):687- 708. https://doi.org/10.1249/MSS.0b013e3181915670.

7. Kraemer WJ, Ratamess NA. Fundamentals of resistance training: progression and exercise prescription. Med Sci Sports Exerc, 2004;36(4):674-688. https://doi.org/10.1249/01.MSS.0000121945.36635.61

8. McLester JR, Bishop E, Guilliams ME. Comparison of 1 day and 3 days per week of equal-volume resistance training in experienced subjects. J Strength Cond Res, 2000;14(3):273-281. https://doi.org/10.1519/00124278-200008000-00006

9. Nakamura Y, Tanaka K, Yabushita N, Sakai T, Shigematsu R. Effects of exercise frequency on functional fitness in older adult women. Arch Gerontol Geriatr, 2007;44(2):163-173. https://doi.org/10.1016/j.archger.2006.04.007

10.Candow DG, Burke DG. Effect of short-term equalvolume resistance training with different workout frequency on muscle mass and strength in untrained men and women. J Strength Cond Res, 2007;21(1):204-207. https://doi.org/10.1519/00124278-200702000-00037

11. Murlasits Z, Reed J, Wells K. Effect of resistance training frequency on physiological adaptations in older adults. $J$ Exerc Sci Fit, 2012;10(1):28-32. https://doi.org/10.1016/j.jesf.2012.04.006

12.Farinatti PT, Geraldes AA, Bottaro MF, Lima MV, Albuquerque RB, Fleck SJ. Effects of different resistance training frequencies on the muscle strength and functional performance of active women older than 60 years. J Strength Cond Res, 2013;27(8):2225-2234. https://doi.org/10.1519/JSC.0b013e318278f0db

13.Fisher G, McCarthy JP, Zuckerman PA, Bryan DR, Bickel CS, Hunter GR. Frequency of combined resistance and aerobic training in older women. $J \quad$ Strength Cond Res, 2013;27(7):1868- 1876. https://doi.org/10.1519/JSC.0b013e31827367e0

14.Peterson MD, Rhea MR, Alvar BA. Applications of the doseresponse for muscular strength development: a review of meta-analytic efficacy and reliability for designing training prescription. J Strength Cond Res, 2005;19(4):950-958. https://doi.org/10.1519/R-16874.1

15.Grgic J, Schoenfeld BJ, Davies TB, Lazinica B, Krieger JW, Pedisic Z. Effect of resistance training frequency on gains in muscular strength: a systematic review and meta-analysis. Sports Med, 2018;48(5):1207-1220. https://doi.org/10.1007/s40279-018-0872-x

16.Calder AW, Chilibeck PD, Webber CE, Sale DG. Comparison of whole and split weight training routines in young women. Can J Appl Physiol, 1994;19(2):185-199. https://doi.org/10.1139/h94-014

17.Gentil P, Fischer B, Martorelli AS, Lima RM, Bottaro M. Effects of equal-volume resistance training performed one or two times a week in upper body muscle size and strength of untrained young men. J Sports Med Phys Fitness, 2015;55(3):144-149.

18. Weineck J. Conditioning in football. Ankara: Sports Bookstore; 2011.

19.Gurbuz MH. Effects of 6-week maximal force training in young men aged 17-22 on physical physiological parameters [Doctoral dissertation]. Selcuk University Institute of Health Sciences; 2013.

20.Castro-Piñero J, González-Montesinos JL, Mora J, Keating XD, Girela-Rejón MJ, Sjöström $M$, et al. Percentile values for muscular strength field tests in children aged 6 to 17 years: influence of weight status. J Strength Cond Res, 2009;23(8):2295-2310. https://doi.org/10.1519/JSC.0b013e3181b8d5c1

21.Gribble PA, Hertel J. Considerations for normalizing measures of the Star Excursion Balance Test. Meas Phys Educ Exerc Sci, 2003;7(2):89-100. https://doi.org/10.1207/S15327841MPEE0702_3

22.Miller MG, Herniman JJ, Ricard MD, Cheatham CC, Michael TJ. The effects of a 6-week plyometric training program on agility. J Sport Sci Med, 2006;5(3):459-465.

23.Andrade VL, Zagatto AM, Kalva-Filho CA, Mendes OC, Gobatto CA, Campos EZ, Papoti M. Running-based anaerobic sprint test as a procedure to evaluate anaerobic power. Int $J$ Sports Med, 2015;36(14):1156-1162. https://doi.org/10.1055/s-0035-1555935

24. Mayhew J, Mayhew D, Ware J, Ball T, Lauber D, Kemmler W. Selecting the best weight to predict 1-RM strength: the 3-5-RM vs 7-10-RM in trained and untrained men. Med Sci Sports Exerc, 2004;36(5): S351. https://doi.org/10.1249/00005768-200405001-01681

25.Ploutz LL, Tesch PA, Biro RL, Dudley GA. Effect of resistance training on muscle use during exercise. $J$ Appl Physiol, 1994;76(4):1675-1681. https://doi.org/10.1152/jappl.1994.76.4.1675

26.Brechue WF, Mayhew JL. Upper-body work capacity and 1RM prediction are unaltered by increasing muscular strength in college football players. J Strength Cond Res, 2009;23(9):2477-2486. https://doi.org/10.1519/JSC.0b013e3181b1ae5f

27.Brzycki M. Strength testing-predicting a one-rep max from reps-to-fatigue. $J$ Phys EducRecreation Dance, 1993;64(1):88-90. https://doi.org/10.1080/07303084.1993.10606684

28.Reynolds JM, Gordon TJ, Robergs RA. Prediction of one repetition maximum strength from multiple repetition maximum testing and anthropometry. J Strength Cond Res, 2006;20(3):584-592. https://doi.org/10.1519/R-15304.1

29.Bompa TO. Periodization of strength: the new wave in strength training. Canada: Veritas Publishing Inc; 1994.

30.Nindl BC, Harman EA, Marx JO, Gotshalk LA, Frykman PN, Lammi E, et al. Regional body composition changes in women after 6 months of periodized physical training. $J$ Appl Physiol, 2000;88(6):2251-2259. 
https://doi.org/10.1152/jappl.2000.88.6.2251

31.Crewther BT, Heke TL, Keogh JW. The effects of a resistance-training training concurrently for rugby union 7's. J Sports Med Phys Fitness, 2013;53(1):34-41.

32.Styles WJ, Matthews MJ, Comfort P. Effects of strength training on squat and sprint performance in soccer players. J Strength Cond Res, 2016;30(6):1534-1539. https://doi.org/10.1519/JSC.0000000000001243

33.Bompa TO, Haff G. Periodization: training theory and method. Ankara: Bagirgan Publishing House; 2017.

34.Baguet G, Guinhouyu C, Dupont G, Noury C, Berthoin S. Effects of a short term interval training program on physcial fitness in prebupertal children. $J \quad$ Strength Cond Res, 2004;18(4):708-713. https://doi.org/10.1519/13813.1

35.Dello Iacono A, Padulo J, Ayalon M. Core stability training on lower limb balance strength.JSports Sci, 2016;34(7):671-678. https://doi.org/10.1080/02640414.2015.1068437

36.Hung KC, Chung HW, Yu CCW, Lai HC, Sun FH. Effects of 8-week core training on core endurance and running economy. PloS One, 2019;14(3):e0213158. https://doi.org/10.1371/ journal.pone.0213158

37.Hermassi S, Van den Tillaar R, Khlifa R, Chelly MS, Chamari K. Comparison of in-season-specific resistance vs. a regular throwing training program on throwing velocity, anthropometry, and power performance in elite handball players. J Strength Cond Res, 2015; 29(8):2105-2114. https://doi.org/10.1519/JSC.0000000000000855

38.Serra R, Saavedra F, De Salles BF, Dias MR, Costa P, Alves $\mathrm{H}$, et al. Effects of resistance training frequency on strength gains. JEPonline, 2015;18(1):37-45.

39.McKenzie G. Effects of frequency of weight training on muscle strength enhancement. J Sports Med Phys Fitness, 1981;21(4):432-436.

\section{Information about the authors:}

Ali E. Cigerci; (Corresponding Author); https://orcid.org/0000-0003-3143-5982; aecigerci@kastamonu.edu.tr; School of Physical Education and Sports, Kastamonu University; Kastamonu, Turkey.

Harun Genc; https://orcid.org/0000-0003-1371-7468; hgenc@bingol.edu.tr; School of Physical Education and Sports, Bingol University; Bingol, Turkey.

\section{Cite this article as:}

Cigerci A, Genc $\mathrm{H}$. The effect of strength training with different frequency on untrained university students. Physical Education of Students, 2020;24(4):186-193. https://doi.org/10.15561/20755279.2020.0401

This is an Open Access article distributed under the terms of the Creative Commons Attribution License, which permits unrestricted use, distribution, and reproduction in any medium, provided the original work is properly cited http://creativecommons.org/licenses/by/4.0/deed.en

Received: 17.04.2020

Accepted: 28.05.2020; Published: 30.08.2020 